\title{
GARANTISMO PROCESAL: UN DEBATE AUSENTE Y UNA ADVERTENCIA CLARA
}

\author{
Claudio Tapia Alvial \\ Universidad de Chile
}

\begin{abstract}
"Si los presupuestos no se examinan' y se dejan al garete, las sociedades corren el riesgo de osificarse; las creencias endurecerse y convertirse en dogmas; distorsionarse la imaginación y tornarse estéril el intelecto (...) Si ha de despertarse la imaginación; si ha de trabajar el intelecto, si no ha de hundirse la vida mental, y no ha de cesar la búsqueda de la verdad (o de la justicia, o de la propia realización), es preciso cuestionar las suposiciones (...) Los hombres y las ideas avanzan, en parte, por parricidio".
\end{abstract}

Isaiah Berlin

\section{INTRODUCCIÓN}

Existe un debate abierto entre dos corrientes doctrinarias, que intentan estructurar el proceso civil ${ }^{1}$, las dos posturas en pugna pueden ser denominadas como publicismo y garantismo. Este debate está abierto en a lo menos dos sentidos, que me gustaría explicitar.

En un sentido trivial del término, cronológicamente el debate no se encuentra zanjado, en especial por las recientes publicaciones, congresos y foros ${ }^{2}$ donde se han expuesto las ideas garantistas, este es un sentido útil por supuesto para este ensayo funda su contingenciä, utilidad e interés.

En este mismo sentido de debate "vivo" se encuadra la crítica realizada por el profesor Palavecino en "El retorno del Inquisidor" -2009- que marca una visión crítica de las reformas vividas por nuestro nuevo proceso laboral, abriéndose por tanto nuestra dogmática nacional a este debate de mayor envergadura entre publicismo y garantismo, que goza de relativa ${ }^{3}$ ausencia en el discurso intelectual nacional de una manera directa.

Una apertura no menor que puede ser sintomática del nuevo rumbo que experimente la discusión académica nacional en materia civil en un corto plazo, en especial si consideramos el dato contingente la puesta en marcha a nivel legislativo de la reforma al proceso civil

\footnotetext{
${ }^{1}$ Esta afirmación no implica señalar que el debate se ha limitado al proceso civil, de hecho en numerosas ocasiones se ha enarbolado el movimiento que han tomado las reformas procesales penales como un argumento a aportar al debate civil, ver BENABENTOS, O. Realidad y debido proceso.

2 El pasado 8 de junio en la Facultad de Derecho de la Universidad de Chile el profesor Alvarado Velloso dictó una conferencia, que se puede enmarcar en la defensa de una postura garantista procesal.

${ }^{3}$ El carácter relativo según el autor se presenta dado que aun cuando no aparezcan los términos, garantismo e ius publicișmo como tales, muchas de las críticas realizadas al nuevo proceso laboral indirectamente enarbolan argumentaciones fácilmente situables de garantistas procesales.
} 
chileno $^{4}$-dicho proyecto fue aprobado por la presidencia y puesto a análisis de la cámara de diputados en junio del 2009-.

Vale la pena repensar hacia dónde y por qué orientamos así nuestra justicia civil, en especial si el nuevo código tomó una posición en el debate ausente de nuestra doctrina.

Asimismo, la implantación de la nueva justicia laboral, que comenzó en marzo de 2008, nos otorga un campo ya cimentado donde evaluar el impacto de ideas del mismo tinte, pues la reforma laboral también había tomado una posición al respecto, siendo así es urgente detener la evasión del tema por la dogmática nacional, resulta necesario comenzar a tratar ¿cuál era dicha posición? Y si ¿esta se encuentra libre de críticas? adelantamos desde ya que la respuesta es negativa, pero merece los matices que este artículo intenta abordar.

Retomando la primera afirmación, en un sentido menos obvio, el debate se encuentra abierto. En un sentido netamente argumentativo, a diferencia de otras discusiones en torno al proceso en las cuales la discusión es esencialmente técnica, el disenso que ha aportado el garantismo como movimiento crítico, permite una lectura política sobre cuestiones que habían sido relativamente pacíficas, un ejemplo de esto se encuentra en la relectura del Codice di Prodicedura Civile italiano de 1940, que propugna la posición teórica aquí analizada y que merecerá algunas consideraciones a lo largo del trabajo, esta misma relectura normativa se ha extendido a buena parte de la historia procesal del siglo XX.

Lo interesante es que este giro argumentativo abre a nuevas dimensiones a tratar en un debate, en principio estrictamente procesal. Cuestión que adelantamos es desde mi perspectiva una ventaja propia del debate y no como un defecto del mismo ${ }^{5}$, es así que introduciré elementos de teoría política con el fin de echar nuevas luces a los valores defendidos por ambas posiciones y un enfoque desde la teoría de la argumentación al momento de hablar sobre el rol de los jueces.

En definitiva, lo pretendido es una revisión teórica al debate publicismo y garantismo, para poder apreciar de una manera adecuada las críticas ya devenidas en nuestro proceso laboral, como las que vendrán al mismo y las futuras al un nuevo proceso civil en trámite legislativo.

Para esto el siguiente Ensayo seguirá la siguiente estructura; 2. La necesidad del debate Publicismo/Garantismo, en la cual se aborda la utilidad y necesidad de este trabajo en el contexto histórico nacional actual. 3. Sobre Garantistas y Publicistas, donde se dará forma al debate, explicando someramente las posturas y sugerir lo que según el autor está detrás o a lo que responden las mismas posiciones, 4. Un problema propio de la tradición Liberal, en el cual se intenta dar la que a juicio del autor responde el movimiento del debate mayor y la falencia del propio movimiento, al desconocer o tener clarificado del todo su posición polí-

\footnotetext{
${ }^{4}$ El proyecto de nuevo CPC, puede ser descargado libremente a través de la página del Ministerio de Justicia, http://www. minjusticia.cl/unidadcoordinadoraRPC/

${ }^{5}$ Aun cuando comparto la pretensión del "replanteamiento" del debate ofrecido por PICÓ I JUNOI, J., "El derecho procesal entre el garantismo y la eficacia: Un debate mal planteado", en: MONTERo, J. Proceso Civil e Ideologia. Valencia: Tirant lo Blanch, Valencia 2006. Se hace evidente que nuestras formas de replantearlos son eminentemente distintas, mi método está en buscar un análisis político de las posiciones en pugna, incluyendo una lectura más amplia respecto de los movimientos políticos involucrados, para repensar el debate.
} 
tica y 5. Sobre el rol de los Jueces, en la cual dado el problema de tensión con la democracia, se hacen algunas breves referencias a lo que debiéramos esperar de nuestros jueces en respeto de la democracia y del Derecho.

\section{LA NECESIDAD DEL DEBATE PUBLICISMO/GARANTISMO}

El ordenamiento jurídico chileno ha sufrido en un lapso de aproximadamente diez años, una alto número de reformas en torno a la justicia ${ }^{6}$, la pretensión de las mismas ha sido la modernización de las normas procesales al tráfico jurídico moderno haciendo que de paso se adecuen a estándares internacionales en lo relativo a administración de justicia, así como acomodar la justicia al desarrollo vivido en cambios culturales y sociales de la sociedad chilena afianzando el modelo constitucional chileno. En definitiva y a riesgo de simplificar el asunto, adecuar nuestro régimen de justicia a los principios que informan un Estado de Derecho contemporáneo.

Consideramos siguiendo a Cappeletti ${ }^{7}$, que en buena medida, el bloque de reformas puede ser entendido por el rol relevante a nivel de proceso que juega el acceso a la justicia ${ }^{8}$, nuestro ordenamiento anterior a las reformas $-\mathrm{y}$ actualmente vigente en cuanto a materia civil- se veía imposibilitado de ofrecer, vulnerando el deber constitucional ${ }^{9}$ del Estado en la materia.

En particular nuestra mirada se cierne sobre la reforma laboral vivida por el ordenamiento jurídico nacional, cuya puesta en marcha comenzó en marzo de 2008 e incluyo la reforma tanto al sistema de recursos, como la implantación de los distintos procedimientos vigentes en la materia; general, de tutela laboral y monitorio.

Desde nuestra perspectiva la única forma de entender la lógica intrínseca que informa la reforma, es apelar a un movimiento aún mayor en el cual se encuentra sumergida, el publicismo procesal.

Siendo así resulta útil tener conciencia del debate que ha traído bajo el brazo el movimiento autodenominado garantismo, puesto este movimiento otorga críticas a la forma en

\footnotetext{
${ }^{6}$ Aun cuando sea tarea más propia de un historiador o sociólogo jurídico, hacer un análisis del movimiento vivido por el ordenamiento chileno en los últimos años, me parece que este periodo se inaugura con la reforma procesal penal e incluye a lo menos el proceso vivido por la justicia de familia -que incluye el subproceso de la mediación, como manifestación de un movimiento mayor en las reformas-, la justicia laboral y en lo que sigue la justicia civil.

${ }^{7} \mathrm{La}$ referencia a Cappeletti dice relación con el proyecto Florencia, "El acceso a la justicia debe considerarse como un derecho humano de importancia primordial", en: CAPPELLETTI, Mauro y GARTH, Bryant. El acceso a la justicia. La tendencia en el movimiento mundial para hacer efectivos los derechos. México: Fondo de Cultura Económica, 1996. p. 11.

8 Aunque esta intención puede ser encontrada en cualquier mensaje de motivación de las reformas, me parece interesante señalar la referencia que realiza el profesor Maturana Miquel en la presentación del anteproyecto del código procesal civil "Se trata de un Código simple, que pretende buscar la eficacia y expedición de la justicia, en un mundo moderno en el cual se ha señalado -no sin razón-que su retardo importa una verdadera denegación, y ha procurado evitar la proliferación de procedimientos que lo único que logran en definitiva es alejar la justicia de la gente y dificultar su conocimiento y aplicación"; en: Revista de Estudios de la Justicia $\mathrm{N}^{\circ}$ 8. Santiago: Universidad de Chile, Facultad de Derecho, p. 45.

${ }^{9}$ Como se llegará a ver, las referencias constitucionales en la materia no son neutrales, por lo que he intentado ser cuidadoso al no utilizar la voz "derecho" propiamente tal, pero si fuese necesario explicitar de mayor manera el sentido en que está siendo utilizado, es como mandato de optimización como Alexy y no propiamerite en el sentido a la Dworkin, de carta de triunfo en contra del Estado, como mera prevención.
} 
que se ha estructurado el proceso civil en los últimos cien años y aunque parezca obvio señalarlo, el proceso civil ${ }^{10}$ y el proceso laboral, guardan cierto parentesco de familia, que no ha sido puesto en duda ni siquiera por la legislación socialista ${ }^{11}$ en su tiempo - "Pertenecen a la categoría de litigios civiles los concernientes a la defensa de los derechos políticos, civiles, familiares, laborales y demás derechos personales patrimoniales, así como de los derechos e intereses protegidos por la ley de los organismos socialistas"12 - por lo que aun cuando vaya a merecer alguna consideración en el desarrollo de este ensayo, las propiedades particulares de la justicia laboral, nos parece totalmente aplicable el marco teórico de un debate propiamente civil.

Del mismo modo si reconocemos el carácter supletorio que guarda el proceso civil en nuestro ordenamiento y el carácter de versiones simplificadas de procedimientos civiles que son los procesos laborales, podremos notar que desde consideraciones interpretativas, a nivel de integración del ordenamiento, el debate resulta atingente.

Además, resulta útil pues considero que el leitmotiv de la reforma laboral, comparte semejanzas con la vivida en la justicia civil en el anteproyecto del nuevo CPC y más aún se encuadra en un bloque de reformas mayor que vive todo nuestro ordenamiento nacional al cual también resulta aplicable la misma macroestructura teórica.

Adelantando en parte nuestras conclusiones, para el autor el debate garantismo/publicismo deriva en una discusión sobre cuál sea el rol que deben cumplir nuestros jueces en un Estado democrático, por tanto el mismo debate cobra importancia si consideramos las palabras de Atria, respecto de la seguidilla de reformas nacionales "En pocos temas ha habido tanta actividad legislativa desde el retorno a la democracia como en materia judicial. Los procedimientos criminales, laborales y de familia han sido radicalmente modificados, y ahora se discute la reforma del proceso civil"13. "[la reforma] deviene completamente irracional si no responde a una concepción de la potestad jurisdiccional, una concepción que identifica la razón de su importancia "14.

$\mathrm{La}$ distancia entre reforma laboral y civil debe ser un tanto matizada a efectos de no caricaturizar el asunto, es así que las críticas particulares que la doctrina laboral había realizado hacia su antiguo proceso apuntaban a la inadecuación con el principio tutelar laboral y con la protección de los derechos constitucionales inespecíficos laborales ${ }^{15}$, consideramos

\footnotetext{
10 Se está utilizando la noción de derecho civil, casi como derecho privado en contraposición a derecho público -derecho penal-, vale decir en un sentido amplio, esta generalidad del término no merece mayores detenciones dado el nivel de generalidad en que se está situando la argumentación.

11 La comparación con la legislación socialista no es gratuita, la discusión relativa a un carácter peculiar del derecho laboral, desde nuestra perspectiva refleja el reconocimiento en este de un sentido público mayor de lo normal que otras áreas del derecho, dicho sentido peculiar de la relación del trabajo y su rol en una estructura mayor expropiatoria, se manifiesta en la doctrina socialista, con lo cual uno podría haber esperado que el proceso laboral tuviese un carácter particularísimo en tal caso, no siendo así.

12 SANTA, J.J. Sistema del derecho soviético. Buenos Aires: Roque Depalma Editor 1957, p. 7.

13 ATRIA, F. "Jurisdicción y estado de derecho", borrador "Jụrisdicción e independencia judicial: El Poder Judicial como un poder nulo", en: Revista de Estudios de la Justicia No 5. Santiago: Universidad de Chile, Facultad de Derecho, 2005 , p. 5.

14 ATRIA, F. op. cit. (n. 13), p. 2.

${ }^{15}$ En tal sentido puede verse UGARTE, J.L. Tutela de derechos fundamentales. Santiago: Editorial LegalPublishing. "La reforma procesal laboral implementada por la Ley $N^{\circ} 20.087$-D.O. de 3 de enero de 2006 - y en particular el procedimiento de tutela,
} 
que esta diferenciación motivacional de la reforma no es en todo caso el único acento para leer la misma ${ }^{16}$ y por eso nos remitimos a un debate más civil al momento de leer sus motivaciones, si colocamos el acento en el acceso igualitario de los sujetos al proceso en un Estado democrático deliberativo, lo que nos pueda aportar el derecho laboral a la hora de estructurar su proceso sumará, pero no restará ni entrará en contradicción ${ }^{17}$ con lo que logremos cimentar, como estándares mínimos de compatibilidad de un proceso con el respeto de los derechos de los individuos en democracia.

Asimismo, la referencia al debate garantista aparte de las razones de entendimiento de los fundamentos de justicia que informan la reforma laboral, ya mencionados, tiene un sentido estratégico a futuro; si consideramos que desde este es posible releer las críticas que se han realizado al proceso laboral reformado, será útil por tanto para prever nuevas críticas y aceptar o rechazar la validez de las hasta ahora realizadas y del mismo modo estas críticas pueden abrir el debate para una nueva línea argumentativa que surja en la doctrina nacional, para criticar el futuro nuevo proceso civil.

\section{SOBRE GARANTISTAS Y PUBLICISTAS}

Durante la segunda parte del siglo XX puede notarse un fenómeno de constitucionalización de las garantías procesales, vale decir un aseguramiento por medio de constituciones y tratados internacionales de un número de garantías mínimas que favorecen a los individuos, sin importar el modelo procesal, este movimiento se ha autodenominado garantis$\mathrm{mo}^{18}$.

el primer paso del orden jurídico laboral por tomar en serio los denominados derechos fundamentales inespecíficos de los trabajadores" p 1 .

16 Una visión encontrada se puede encontrar en Pulgar, quien se queja de un sistema procesal "tan lamentablemente civil", en: Pulgar, Carlos. “¿Existe un Derecho Procesal del Trabajo?”, en: Boletín Oficial de la Dirección del Trabajo. Santiago, febrero 2006, p. 8.

${ }^{17}$ Esta afirmación da para un nuevo debate, pero me conformo con señalar al respecto que la considero compatible con la idea de racionalidad de la ley procesal en sentido instrumental de Taruffo-al menos-, en: TARufFo, Michele. "Racionalidad y crisis de la ley procesal", en: $D O X A, \mathrm{~N}^{\circ} 22$. Alicante, 1999, p. 312. "Se puede estar de acuerdo en líneas generales en el hecho de que, si lo que se espera de un proceso son cosas como la actuación de la ley en el caso particular, la formulación de decisiones justas y la efectiva tutela de los derechos de los sujetos interesados, se puede encontrar, al menos un punto de referencia general".

${ }^{18}$ Cabe hacer aquí unas cuantas prevenciones metodológicas, tal como señala el Cipriani a propósito de unas palabras de Giovanni Verde "como señala el Profesor Verde, oralidad, socialización, concepción pública del proceso civil, etc. Son expresiones que condensan una amalgama de postulados de difícil precisión; de modo que cada una de ellas es más un slogan que otra cosa", vale decir, tratamos con temas que tienen cierta ambiguiedad, publicismo y garantismo son temas que quieren decir varias cosas, por lo mismo el intento de realizar una precisión terminológica de cada tema que cada uno trata o de decidir de una manera que tenga expectativas de exhaustividad, es un reto académico que no me encuentro actualmente en el nivel para realizar por lo que mi apuesta es sutilmente distinta, intentar entender que nociones fundan tales movimientos, realizando ciertas apreciaciones de consecuencias de los mismos en determinados temas, recalco sin pretensión de exhaustividad y que por supuesto admiten debate sobre si mi caracterización es la mejor -toma lo suficientemente en serio la postura- o no.

Asimismo dentro del trabajo se ha optado por tratar los términos garantismo y publicismo, entendiendo a cada una de estas posturas como un fenómeno a nivel de movimiento consolidado, que en todo caso no niega las contradicciones internas entre autores situables entre una y otra vereda, guardando el margen de consistencia general del movimiento. 
Aunque carece de sentido pretender realizar una lista taxativa de los autores que pertenecen a este movimiento ${ }^{19}$, puede resultar ilustrativo nombrar a los más representativos en ésta línea; Cipriani y Montteleone en Italia (los también denominados revisionistas), Montero Aroca en España, y Alvarado Velloso en Argentina.

Las propuestas y consecuencias del garantismo procesal son variadas ${ }^{20}$, por lo que en lo relativo a este trabajo solo haré referencia a unas cuantas intentando con ellas sintetizar el margen general de la postura, así y todo puede señalarse que este tiene como característica compartida sea por cual sea el autor que tratemos dentro de la corriente, la de contraponerse de manera crítica al llamado publicismo procesal o modelo "socializador".

En contraposición al modelo anterior se halla el publicismo procesal, podemos encontrar el origen histórico del publicismo en los trabajos de Franz von Klein, que culminan con la ordenanza procesal austriaca de $1895^{21}$, la que repercute en el Código de Proceso civil de 1939 y el Códice di Procedura Civile 1940, asimismo este habría influenciado a numerosos códigos en Latinoamérica, entre los cuales cabe hacer referencia -dado que se han realizado análisis críticos a tal influencia desde autores garantistas- al código peruano de 1993 y el caso portugués, asimismo el profesor Alvarado Velloso ha realizado críticas contundentes al actual estado del ordenamiento argentino, desde una postura garantista: "El mundo está yendo hacia un totalitarismo procesal angustioso y angustiante. Primero nos cambiaron las reglas del juego con las cargas (...); segundo, posibilitaron que el juez tomara irrestrictamente las medidas para mejor proveer; tercero inventamos la medida innovativa; cuarto, hemos inventando la autosatisfactividad"22.

El impacto en cuanto al contenido de los ya nombrados cuerpos normativos puede caracterizarse del siguiente modo, existe una comprensión del proceso no únicamente como una cuestión entre partes, sino que se le reconoce al proceso un rol social, un asunto público, por lo tanto el conflicto llevado ante tribunales, no es un conflicto exclusivo de las partes, sino que reviste un carácter público aun cuando esté siendo utilizado por privados ${ }^{23}$, la racionalidad implícita en dicha posición es que el proceso es un "mal" no solo en el sentido económico, donde implica cierta disposición de recursos por parte del Estado y que deban ser defendidos por el mismo, sino porque el conflicto mismo de los privados importa males que tienen consecuencias que los sobrepasan a los mismos, siendo el Estado el que debe asumir con las externalidades negativas del conflicto.

Esto tiene como consecuencia teórica que se deban acrecentar los poderes del juez para transformarlo en director del proceso: "frente al modelo clásico del juez pasivo iner-

\footnotetext{
19 Tal intento se vuelve inútil tanto por: i) límite de información a la que tengo acceso, ii) cuestión cronológica, se han e irán integrando más miembros según sea el impacto que la postura tenga y iii) carece de utilidad, salvo que mencione a los más connotados.

${ }^{20}$ Un intento más elaborado de enumerar directamente reformas procesales que implica una postura garantista, puede verse en BENABENTOS, O. op. cit. (n. 1.).

${ }^{21}$ Según Adolfo Schönke, es la reforma procesal civil que más ha influido en toda la época moderna, ver en: SCHÖNE, Adolfo. Derecho Procesal Civil. Barcelona: Bosch Casa Editorial, 1950. p. 15.

22 Montero, J. "Prólogo", en: Montero, J. op. cit. (n. 5), p 13.

${ }^{23}$ La idea se puede ver claramente y probablemente mejor formulada que por mí en ETXEBERRIA, J. Las Facultades judiciales en materia probatoria en la LEC. Valencia: Tirant lo Blanch, 2003.
} 
te, pasa a ocupar una posición activa en el proceso. En la medida en que tiene asignada la función pública de resolver los conflictos, se considera que deben atribuírsele las iniciativas necesarias para lograr la máxima eficacia" 24 y para que su labor resulte eficaz, deberá orientarse a la búsqueda de la verdad. En la clásica metáfora usada por Calamandrei "nadie obliga al particular a subir sobre la nave de la justicia, y si él mismo decide embarcarse en ella, a él solo le corresponde fijar el inicio y la meta del viaje; pero una vez emprendida la navegación, el timón debe confiarse exclusivamente al juez, que tiene durante el viaje la responsabilidad de la derrota" 25 .

Asimismo, el publicismo tiene como consecuencia directa una reducción del principio dispositivo, en términos de Claudio Palavecino la "jibarización" del principio dispositivo, de modo tal que "sin discutir la vigencia del principio dispositivo -disposittionsprinzip-, va a ponerse en tela de juicio el de aportación de parte -verhandlungsmaxime-, al menos por lo que respecta al reparto de funciones entre el juez y los litigantes" ${ }^{26}$. Esto puede explicarse del siguiente modo: la formulación liberal clásica concebía al principio dispositivo de manera amplia, conteniendo en él la aportación de parte; el impulso procesal para el inicio y avance del proceso y la determinación de su objeto. El movimiento publificador reduce su contenido, separando el principio de aportación de parte y el impulso procesal y como consecuencia de tal operación pasa a ser compatible con el principio dispositivo un sistema con un juez que cumple un rol activo, que puede investigar oficiosamente y un impulso procesal compartido, "si bien los litigantes son libres de disponer de los intereses deducidos en juicio, o sea del objeto del proceso, no lo son respecto del proceso mismo" 27 .

De la misma manera el movimiento trajo consigo una serie de reformas orientadas a darle celeridad al proceso; oralidad, deberes de buena fe procesal, inmediación, concentración, reestructuración de los recursos, facultades probatorias del juez, etc. Autocomprendidas como opciones técnicas como la mejor manera de cumplir con el modelo de entender el rol del tribunal ${ }^{28}$.

\footnotetext{
${ }^{24}$ PICÓ I JUNOI, J. op. cit. (n. 5), p. 110.

${ }^{25}$ ETXEBERRlA, J. op. cit. (n. 23), p. 31.

26 PICO I JUNOI, J. op. cit. (n. 5), p. 110.

27 Ibid.
}

${ }^{28}$ Sobre el modelo de entender el rol del tribunal vale tomar en consideración, la existencia de dos grandes modelos de sistema procesales, Inquisitivo y Dispositivo, el primero coloca una preeminencia del Estado por sobre la parte y en el segundo la parte es el centro del proceso, como se verá básicamente la acusación garantista consiste en señalar que el proceso civil publicista es Inquisitivo, propugnando tanto para derecho civil como para derecho penal, un proceso dispositivo -o acusatorio en materia penal-. Esta visión también reniega la posibilidad de modelos mixtos, tanto para uno como para otro, como se entenderá esto es pues no es concebida la adopción entre uno y otro como una opción técnica, cuestión que sí hace el Publicismo, sino como opciones políticas. La lógica por tanto sería la siguiente, si la forma Inquisitiva es autoritaria -como sostiene el Garantismoesta no puede informar ningún proceso, puesto pasar por encima de las garantías de los individuos sea cual sea el caso, sea cual sea la materia. Una afirmación de este tipo puede encontrarse en BENABENTOS, O. op. cit. (n. 1.), p. 1. "El garantismo pretende implementar un diseño netamente dispositivo para el proceso civil, y acusatorio, en el proceso penal. Solo bajo la adopción de este esquema los códigos procesales latinoamericanos se tornaran congruentes con el dibujo constitucional del "debido proceso". Una posición crítica en cambio a la utilización de los términos inquisitivo y negación de los sistemas mixtos se puede ver en TARUfFo, Michele. op. cit. (n. 17). "El término "inquisitorio" es, por tanto, confuso porque no ha existido nunca, y no existe hoy en ningún ordenamiento, un proceso civil que pueda considerarse verdaderamente inquisitorio: es decir, en el que las partes no tengan derechos o garantías y todo el proceso sea impulsado de oficio por el juez. De otra parte, no es el caso 
El fenómeno alcanza predominio en la dogmática impregnando la mayoría de los códigos del siglo XX, situando en esta línea las reformas vividas por nuestra justicia laboral 29 así como también impregna al anteproyecto del nuevo CPC.

Ahora bien, tal como se señaló este movimiento -más o menos articulado-, ha recibido recientemente críticas de la postura garantista, la cual aunque menor en número de miembros no es por tanto desestimable, en especial por la reciente victoria que se ha adjudicado el movimiento en relación a la nueva ley de Enjuiciamiento Civil española. "En cambio, la irrupción normativa del "garantismo" en el proceso civil es reciente y ha tenido su primera concreción en España, recién a partir del año 2000. Ese país ha sido el pionero en abandonar modelo procesal "neoinquisitivo" para sustituirlo por una moderna, democrática y liberal ley de enjuiciamiento civil" 30 .

Las críticas tienen diversas ramificaciones argumentativas, pero aquella en que me interesa concentrarme en el presente trabajo es la crítica política o de adjudicación de rol político a la postura publicista.

Dicha crítica puede ser explicada del siguiente modo, las opciones de justicia como opción técnica tomadas por parte de la visión publificadora o socializadora no serían:

1) Como señalan sus gestores, opciones de los mejores medios para alcanzar un fin, puesto dicho fin es eminentemente político, en palabras de Alvarado Velloso el modelo publificado sufre de cierto maquiavelismo que justifica fin sin importar los medios, "ese método perverso, espantoso, justificando la meta por sobre el método, fue tomado por las leyes procesales, ese es el famoso principio del sistema inquisitivo que nos rige y que sigue rigiendo hasta hoy en un motón de lugares en América Latina" ${ }^{31}$ y;

2) Dado que ha sido gestado, en códigos de los cuales el garantismo duda de su asepsia ideológica. En palabras de Montero Aroca estas dos ideas pueden ser expresadas como sigue:

"la concepción publicista del proceso civil hunde sus raíces en una ideología autoritaria y fascista, en que el aumento de poderes del juzgador entrañaba en realidad la abolición del protagonismo de las partes en el proceso". Y "No hay códigos neutrales, hablando políticamente, y todos debemos ser conscientes de la base ideológica del código que nos rige, entre otras cosas porque la interpretación de muchas de sus normas

\footnotetext{
que la tradicional contraposición entre proceso adversarial y proceso inquisitorio esté privada de validez sobre el plano de la comparación entre modelos procesales. Por estas razones parece particularmente útil una operación de terapia lingüística consistente en dejar de usar el término "inquisitorio", al menos con referencia al proceso civil. Es más oportuno hablar de modelos mixtos para indicar aquellos ordenamientos procesales -que actualmente son muy numerosos- en los que se prevén extensos poderes de instrucción al juez, junto a la plena posibilidad que las partes tienen de deducir todas las pruebas admisibles y relevantes para la comprobación de los hechos".

${ }^{29}$ Es de ese modo como podemos leer el artículo 425 de nuestro Código del Trabajo, que señala los principios a que aspiran los procedimientos laborales.

30 Benabentos, O. op. cit. (n. 1.), p. 2.

31 Alvarado, A. "El garantismo procesal", Conferencia pronunciada en el Primer Congreso Nacional de Derecho Procesal Garantista, Azul, 4 y 5 de noviembre de 1999. p 3.
} 
depende de esa base. Hoy nadie puede sostener, como Stein en 1921, que el proceso civil está regido por derecho técnico en su máxima expresión, el cual por ello carece de valores eternos" 32 .

La apelación a que la base ideológica de un código es de determinada tendencia política y que esta impregne por tanto a las instituciones que del mismo se desprenden, ha sido especialmente conflictiva en torno al Códice di Prodicedura Civile italiano de 1940, esta lectura del mismo ha sido provisionada por Cipriani y Monteleone en Italia y en España por Montero Aroca.

El argumento histórico es indudable y está cómicamente expuesto por Cipriani "el código de procedimiento civil italiano, aquel promulgado en 1940 y que casualmente o pour cause lleva las firmas de cavaliere Benito Mussolini y el conde Dino Grandi, sería antiliberal y autoritario y, como tal fascista", asimismo dicha lectura se apoya también en la relación que Dino Grandi hace en el mensaje de dicho CPC, "Si el Código de 1865 fue, por razones históricas de las cuales no se había tal vez apercibido ni sus autores, la expresión de aquellas premisas individualistas en que se basaba el estado liberal, el Código de 1940 pretende ser, con resuelto conocimiento, la expresión histórica del Estado fascista y corporativo". La lectura ha sido especialmente controvertida, pues ha modificado la visión clásica respecto del hasta entonces sacralizado Calamandrei.

Cabe hacer mención para tantear los ánimos en el debate intelectual, que los sujetos que han defendido esta tesis han sido denominados revisionistas, este mote fue puesto por Chiarloni, cabe hacer evidente lo despectivo ${ }^{33}$ del apodo, en su acepción peyorativa el término significa una manipulación de la historia con fines políticos ajenos al rigor intelectual.

Este ánimo es del todo reprochable pues no toma el peso racional necesario al argumento contrario. Mi posición respecto al tema, es que la cuestión no es tan trivial como si el código es o no autoritario por las razones históricas ya mencionadas, en tal caso revestiría el argumento la forma de la falacia popularizada por Leo Strauss, de la reductio ad hitlerum $-\mathrm{x}$ es malo porque $\mathrm{x}$ era apoyado por Hitler-, si lo fuese valdría también por ejemplo como argumento en descrédito de la búsqueda de la verdad -y de hecho es utilizado por los garantistas $^{34}$ - que por ejemplo el ordenamiento civil soviético se ordena a la búsqueda de la verdad

"Un postulado importantísimo para la aplicación del Derecho, al realizarse la justicia socialista, lo constituye la comprobación exacta de los hechos en cada caso concreto, con los que la ley relaciona la vigencia de determinada norma jurídica. Los tribunales

\footnotetext{
32 Montero, J. op. cit. (n. 5), p. 16.

33 Por un análisis del significado y las consecuencias del término revisionista puede ser encontrado en Monteleone, G, op. cit., p. 176.

${ }^{34}$ Por ejemplo Alvarado Velloso explícitamente se refiere al punto señalando que "para eso había que hacer que los jueces estuvieran comprometidos con su tiempo, que los jueces estuvieran compromeridos con las ideas del partido político gobernante, que los jueces salieran a buscar dos banderas que eran y son de la mayor importancia y que eran; la verdad y la justicia. Y esa es la norma que aparece textualmente en el artículo 17 del código procesal de la URSS" que se toca con el código nazi de 1937 y que "cuaja con el código procesal italiano de 1940." Alvarado, A. op. cit. (n. 31), p. 4.
} 
deben dilucidar en todos los litigios las verdaderas circunstancias del caso, así como los derechos y las obligaciones de las partes. Dicho en otros términos, los tribunales deben empeñarse por todos los medios en establecer la verdad objetiva en todos los litigios. Solo de este modo puede asegurarse la auténtica defensa de los derechos soviéticos todos los medios necesarios para la sustanciación del proceso" 35 .

Esa manera de mirar el problema no permite a mi parecer que el argumento sea tomado en serio, si miramos por ejemplo nuestro Código Civil descubriremos que el criterio histórico es tan solo uno de los considerados, al momento de comprender el significado de una norma, por supuesto que existe ${ }^{36}$ pero es tan solo uno más ${ }^{37}$ en esto seguimos a Picó "La bondad técnica (o validez de una norma depende de su propio contenido y alcance, más que de la época en que haya sido redactada, de la ideología de su autor o de la forma en que se aplique en la práctica forense" ${ }^{38}$, es así que optamos por una mirada hermenéutica global al mirar las normas, en especial si pensamos que el argumento histórico parece ir en retirada desde la teoría argumentativa interpretativa.

Lo que sí resulta interesante de la crítica realizada por el garantismo, es la posibilidad de leer a nivel de discusión procesal como un problema de tradiciones políticas en pugna, básicamente los garantistas tildan al modelo publicista, que tiene orígenes políticos diversos -autoritarismo sea de derecha e izquierda-, de contrario a las ideas liberales. Esta noción está en Alvarado Velloso y Montero Aroca respectivamente "la ideología es bueno, si no es Autoritarismo, si esto es el Liberalismo que me prometieron en nuestra Constitución o es el decadente Autoritarismo fascista del año 40"39 y "se evidencia como de un modelo liberal propio del siglo XIX, se ha pasado a modelos autoritarios en el siglo XX". Sobre si la crítica es hacia el totalitarismo o al autoritarismo de ciertos ordenamientos, es una polémica de largo aliento, por eso he sido cuidadoso en llamar a la crítica garantista una adjudicación de autoritarismo a su posición contraria.

El problema no es menor, totalitarismo y autoritarismo no son recipientes sellados al vacío que no admitan discusión si la distinción es o no sustancial, lo que sugiero simplemente es que la crítica de autoritario de ciertos códigos, ha llevado implícita una carga política enorme que ha implicado confusiones, entre los mismos autores.

Lo que sostendré a continuación es que dicha dimensión rescatable de la crítica garantista responde a un problema aún mayor, un problema que se relaciona con la tradición liberal como tal, con la noción de democracia y su relación con el liberalismo. El valor de la discusión ha sido relativizado al no tomarse en cuenta lo político de la posición garantista.

\footnotetext{
${ }^{35}$ CIPRIANI, F. "El autoritarismo procesal -y las pruebas documentales-", en: Ius et Praxis, vol. 13, $\mathrm{N}^{\circ} 2$. Talca: Universidad de Talca, Facultad de Derecho, 2007, p. 10.

${ }^{36} \mathrm{El}$ argumento histórico ha sido puesto en duda a nivel interpretativo constitucional donde la amplitud de la norma es mayor.

37 Debo prever la posible crítica de que dado que tratamos con normas propiamente procesales y están -debieran-carecer de vaguedades, los criterios interpretativos, en su conjunto debieran rara vez llegar a ser utilizados, por lo que solapadamente por esa imposibilidad fáctica, relativo al punto conviene leer TARUFFO, Michele. op. cit. (n. 17).

${ }^{38}$ PICO I JUNOI, J. op. cit. (n. 5), p. 114.

${ }^{39}$ Alvarado, A. op. cit. (n. 31), p. 10.
} 
Entendiendo que lo rescatado por mí de la postura garantista, responde a esta dimensión teórica mayor, deviene entonces en una discusión sobre cuándo un sistema procesal es compatible -o no- con la democracia y para esto es necesario previamente tener nociones claras sobre la tradición política a la que debe su cuño el garantismo.

Por democracia aquí entiendo como Prost, no un concepto vago, sino distinguiéndola de la mera

"soberanía popular y mayoritarismo porque democracia es una idea normativa que se refiere a valores políticos sustantivos, mientras que soberanía popular y mayoritarismo son términos descriptivos que se refieren a particulares procedimientos de toma de decisiones" 40 y "La democracia requiere solamente que sean mejoradas las desigualdades que socavan la legitimidad democrática. No requiere esto por razones de imparcialidad o justicia distributiva, ni por ningún compromiso filosófico que se encuentre fuera del debate democráticos y de toma de decisiones sino simplemente porque esas desigualdades socavan la legitimidad democrática. La democracia no requiere la rectificación completa de estas desigualdades, sino la rectificación necesaria para mantener la legitimidad democrática" 41 .

Ese quantum mínimo de igualdad que debe ser garantizado a los sujetos, no es otra cosa al nivel que nos aboca, que estos sean iguales en el proceso. Con esto entenderé que sus intereses puedan ser tomados en cuenta al momento de la decisión, es por eso que la parte final de este ensayo se abocará a realizar ciertas explicaciones sobre el rol de los jueces.

Puede encontrarse una correlación entre las ideas de autoritarismo, liberalismo y critica finalmente a la antidemocracia en Barbosa Moreira, quien sintetiza la postura garantista como aquella que señala "El incremento de los poderes del órgano judicial, asevérase, es típico de legislaciones autoritarias, emanadas de gobiernos antidemocráticos e indiferentes a las garantías de los litigantes".

Recapitulando, la crítica garantista es una crítica política -en esencia- y en eso reside su valor, pues logra alcanzar la pregunta sobre si nuestro sistema procesal es compatible, tal como se ha estructurado en buena parte del siglo XX con la democracia, entendiendo esta como un valor político que resguarda un mínimo de igualdad - sin apelar a nociones distributivas- entre los ciudadanos, para utilizar un lenguaje más simple y aterrizándolo al contexto nacional ¿es nuestro proceso laboral -también es aplicable la pregunta al futuro sistema civil-, configurado conforme a un idea de proceso publicista, compatible con la democracia?, ¿pasa el test mínimo de igualdad de trato que nos deben nuestros jueces en democracia?, estas son las preguntas que hace visible el garantismo procesal y ahí reside su valor.

Para iluminar en parte dichas interrogantes la siguiente sección será dedicada a ciertas consideraciones relativas a la tradición liberal y posteriormente a algunas cuestiones sobre lo que deben realizar nuestros jueces al momento de decidir.

\footnotetext{
40 Prost, R. "Democracia e igualdad" [disponible en: www.law.yale.edu/intellectuallife/selapublication.html]

41 Ibid.
} 


\section{UN PROBLEMA PROPIO DE LA TRADICIÓN LIBERAL}

\section{¿Qué es la tradición liberal?; ¿Quiénes la constituyen?; ¿Existe un cuerpo organizado} de ideas y consecuencias de la misma?; ¿Cómo se relaciona esta con la democracia? Estos son problemas ingentes de los cuales no me puedo hacer cargo de una manera exhaustiva ${ }^{42}$, por lo que en lo que sigue me veo radicalmente obligado a tomar una opción: plantear el problema. -Esta advertencia es de suyo necesaria pues existen otras formas alternativas de establecer las delimitaciones que pueden tener mucho más merito histórico/político que la mía y que de seguro será discutible si es de agrado de los garantistas y si representa o no verdaderamente la pugna en juego- ${ }^{43}$.

\footnotetext{
${ }^{42}$ Tanto por las consideraciones obvias de extensión y atingencia al tema tratado, como a conocimientos del humilde autor, no soy un historiador de las ideas como para poder tomar con todo el peso la envergadura del problema, en todo caso espero que la forma de plantear el problema, sea mínimamente consistente y coherente con el problema tratado.

43 Hay una polémica de suma importancia para el enfoque que del problema que estoy intentando, tal como ya se ha señalado anteriormente la cuestión de una adjudicación política al garantismo no ha sido exenta de debate, en particular me interesa el ocurrido entre Taruffo y Cipriani. A continuación realizo algunas citas de Taruffo algo extensas pero que considero necesaria; "si los poderes de instrucción del juez pueden ser considerados como un problema polírico, o sea si la atribución al juez de poderes de iniciativa de instrucción implica la asunción de una ideología política antiliberal y sustancialmente autoritaria, o incluso totalitaria. La cuestión no es nueva, y ha generado discusiones recurrentes en la doctrina del proceso civil. Sin embargo ella es objeto de un reciente revival, particularmente en Italia y en España, pero también en otro lugar, así que acerca de esto es oportuno hacer algunas consideraciones.
}

No es posible aquí examinar la tesis en todas sus versiones y variantes: en sustancia, tal tesis afirma que la presencia de un juez dotado de poderes de instrucción autónomos sería uno de los indicadores seguros del hecho de encontrarnos en un sistema autoritario, mientras un sistema auténticamente liberal no debería atribuirle al juez ningún poder de iniciativa de instrucción. No está claro, en los términos en que generalmente esta tesis es expresada, si se entiende que sería autoritario y antiliberal el proceso en el que el juez cuenta con poderes de instrucción autónomos, o si se tiene que considerar como autoritario, totalitario y antiliberal también el sistema político en el que semejantes poderes le son atribuidos al juez civil. En la primera hipótesis, todo el discurso amenaza a reducirse a un juego circular de definiciones: en realidad, se puede llamar "autoritario" al proceso en que el juez tiene poderes de instrucción, y llamar "liberal" al proceso en que el juez está privado de tales poderes. Esto en el empleo lingǘstico es bastante común, aunque pueda parecer incongruente definir como simplemente "liberal" un proceso caracterizado por el monopolio de las privados sobre los medios de prueba, puesto que un proceso semejante pudiera ser "no liberal" bajo otros puntos de vista, por ejemplo no asegurando la independencia del juez. El primer uso lingüístico es aún más incongruente ya que un proceso en que el juez cuenta con poderes de instrucción no implica ningún "autoritarismo" procesal, pudiendo tales poderes configurarse como puramente supletorios y complementarios con respecto de los de las partes, y pudiendo el juez desarrollar un papel completamente secundario, o marginal, en la recolección de las pruebas.

Además, como a menudo ocurre, el juez puede prescindir de ejercer sus poderes, así que no se tendría, en realidad, ningún gesto autoritario en la instrucción probatoria. Este modo de usar el lenguaje no es, en todo caso, neutral, en virtud de la valoración negativa que el uso retórico del término "autoritario" le da al proceso en que el juez está dotado con poderes de instrucción, y de la valoración positiva que el término "liberal" retóricamente otorga al proceso en que el juez está privado de tales poderes. Se trataría pues de un juego de definiciones determinadas no particularmente útil pero tampoco inocuo: es en todo caso oportuno no valerse de definiciones semejantes, ya que ellas parecen precursoras de confusiones y tergiversaciones. La segunda de la hipóresis antes indicada (o sea, aquella según la cual existiría una conexión directa entre la presencia de poderes de instrucción del juez y la naturaleza autoritaria del sistema político en la que tales poderes son previstos) parece tener un contenido más serio y laborioso y, por lo tanto, merece alguna ulterior mención. En sus versiones corrientes, esta orientación es incierta por varias razones, relativas ante todo, a la falta de una teoría política creíble y suficientemente articulada. Por ejemplo, generalmente no se distingue entre los muchos tipos de régimen político que, en su momento, son calificados como autoritarios, poniendo junto cosas bastante diferentes como el fascismo, el comunismo, el socialismo, el Estado asistencial e intervencionista, el Estado social, etcétera. De este modo la calificación de "autoritario" se hace así vaga y genérica por resultar sustancialmente falto de sentido. De otra parte, no se distingue ni siquiera entre las varias especies de liberalismo, así que no se logra comprender si se habla de la concepción de Nozick, de Rawls, de Mill, de Hayek, de Croce o de algún otro exponente de 
Friedrich Hayek, en su famoso ensayo de 1966, Los principios de un orden social liberal se hace cargo parcialmente del problema, este distingue como liberalismo una determinada concepción de orden político ${ }^{44}$, que $-\mathrm{y}$ esto es lo que nos resulta especialmente útil- se distingue de otra concepción también llamada "liberal", esta corriente de liberalismo aparente, tiene su origen en Francia y fue en términos del autor motivado un por un

la teoría política liberal. En realidad, los partidarios de la orientación que aquí se considera no se interesan en la teoría política, y menos se preocupan por definir los conceptos políticos que emplean. Resulta sin embargo claro cuál es el tipo de sistema liberal al cual se dirigen sus preferencias: estos son -genéricamente- aquellos sistemas del siglo XIX en los que estuvo vigente las concepciones del proceso civil típico del individualismo propietario, con la exaltación de la autonomía de las partes como valor absoluto y prioritario de actuar a cualquier coste, y privilegiado con respecto a cualquier exigencia de funcionalidad y eficiencia del procedimiento.

Además, no se considera que la contraposición fundamental, como se observa en la ya clásica obra de Neumann, se dé entre liberalismo y autoritarismo, sino entre Estado democrático y Estado autoritario. La diferencia es importante porque han existido sistemas políticos que se inspiraron para algunos aspectos en la ideología liberal pero que ciertamente no pueden ser definidos como demócratas. La Italia de la segunda mitad del siglo XIX -al que algunos defensores del revival hacen referencia- fue por algunos calificada como "liberal", y lo fue en particular en el ámbito de la justicia civil, puesto que el juez configurado por el código procesal del 1865 fue sustancialmente pasivo y no contó con poderes de instrucción autónomos. Sin embargo el régimen de la época no fue ciertamente democrático, puesto que -para citar un solo aspecto- el derecho a voto correspondió solamente a un reducido porcentaje de ciudadanos varones. De otra parte, han sido varios los regímenes autoritarios en los que el proceso civil permaneció como monopolio de las partes con respecto a la dirección del proceso y a la disponibilidad de los medios de prueba: basta pensar en el código napoleónico de 1806, que sirvió luego de modelo a numerosas codificaciones del siglo XIX, al reglamento procesal austriaco del 1815, a la Italia fascista, donde hasta 1942 estaba en vigor el código "liberal" del 1865, o a la España franquista, en el que estaba en vigor la "liberal" Ley de enjuiciamiento civil del 1881.

Por oposición, existen numerosos sistemas demócratas en los que el juez cuenta con amplios poderes de instrucción, como ocurre p.e. en Francia, en Suiza y en Alemania. En resumen: es verdad que los sistemas que se inspiraron en la ideología liberal clásica han producido ideologías procesales vinculadas a la presencia de un juez pasivo y al monopolio de todos los poderes procesales y probatorios reservado a las partes: es cuanto se ha verificado, por ejemplo, en los Estados Unidos con la configuración del adversarial system of litigation, en Italia con la codificación procesal del 1865, y en casi todas las codificaciones procesales del siglo XIX. No es verdad, en cambio, que los régimenes soi-disant liberales tengan o hayan tenido sistemas procesales con un juez falto de poderes de instrucción. Por oposición, incluso es verdadero que algunos regímenes autoritarios, como el soviético, han extendido de modo relevante los poderes de instrucción del juez, pero también es verdad que no todos los regímenes autoritarios lo han hecho, como demuestran los ejemplos antes referidos de la Italia fascista, de la Alemania nazi y de la España franquista. (...)

Consideraciones generales de este género serían probablemente suficientes para demostrar que las ecuaciones del tipo "poderes de instrucción del juez = régimen autoritario" y "juez pasivo = régimen liberal" son vagas y genéricas, y se reducen a eslóganes polémicos faltos de valor científico. Ya que, sin embargo, estas ecuaciones corresponden a posiciones bastante difundidas, merece la pena determinar si por casualidad ellas tengan algún fundamento bajo la perspectiva comparativa e histórica. TARUFFO, Michele. op. cit. (n. 17).

Por su parte Cipriani respondió a estas afirmaciones en su artículo "El autoritarismo Procesal (y las pruebas documentales)" entre estas hay unas cuantas "metodológicas" que atacan el desprolijo desarrollo que habría realizado Taruffo, espero no ser yo sujeto de críticas similares. Mi intento se enmarca en la pretensión de Taruffo de dilucidar que tradiciones están envueitas en la disputa, he de asumir que mi intento de tomar publicismo y garantismo, como cuerpos estructurados -aun cuando realmente no lo sean-podría recibir la crítica de Cipriani de estar tratando con eslóganes, que no toman el peso necesario a la postura, mi pretensión no podría ser sino la contraria, además el hecho de que Cipriani haga las diferenciaciones entre su postura y un liberalismo a secas, no significa que mi análisis carezca de validez para todo el resto de los autores.

Considero en definitiva que es un problema de método, he optado por tratar como movimientos y estructurar lineamientos generales, lo que tiene por consecuencia que inevitablemente uno o varios autores que se sientan parte de la tradición, puedan no sentirse acogidos por mi descripción de la misma. Sin embargo he escogido esta forma de tratar el asunto porque me da la libertad de no caer en minucias respecto de mi objetivo general.

${ }^{44}$ Lo notable de Hayek es que amablemente nos señala desde qué año comienza, listado de autores que fundan dicha tradición y los consecuentes autores que se vicron influenciados por la tradición, para ver más HAYEK, F. Los principios de un orden social Liberal. Disponible en: www.cepchile.cl 
espíritu constructivista y que fue el precursor del socialismo moderno, según el mismo este "liberalismo" se convirtió más bien en un democratismo, cuestión que nos sirve de pie para entender la relación del liberalismo con la democracia.

"Liberalismo [el verdadero] y democracia, aunque compatibles no son lo mismo. Al primero le incumbe la extensión del poder gubernamental; al segundo, quien detenta este poder. La diferencia se advierte mejor si consideramos sus opuestos; el opuesto de liberalismo es totalitarismo, mientras que el opuesto de democracia es autoritarismo (...) un gobierno democrático pueda ser totalitario y que un gobierno autoritario pueda actuar sobre la base de principios liberales" 45 .

De la enunciación de Hayek salta a la luz el problema de la relación del liberalismo con la democracia, hay que distinguir la cuestión de cómo se relaciona el liberalismo con la democracia de la pregunta de cómo se relaciona el "democratismo" con la democracia. El problema es bien expresado, según mi parecer, por el profesor Carlos Peña:

"lo que tienen en común tanto la tradición liberal como la tradición democrática es la búsqueda de ese momento incondicional, de ese momento de universalidad que hace posible a la normatividad, si eso es lo que tienen en común digo la tradición democrática y la tradición liberal ella se diferencia en cambio a la hora de intentar resolver ese problema. Tienen el mismo problema pero intentan resolverlo, me parece de maneras distintas. Mientras la tradición liberal instituye al individuo en su relación con la naturaleza, mediante el trabajo y la propiedad como ese momento de incondicionalidad, la tradición democrática represada aquí por Rousseau pero que uno podría extender por ejemplo hasta Habermas, instituye en cambio la comunidad política, a la formación de una voluntad común, como ese momento originario" 46.

Es así que considero que el problema no advertido por el garantismo al imputar autoritarismo ${ }^{47}$ al publicismo, está en no tener claridad sobre a qué liberalismo debe su cuño liberal, tal como señala Taruffo siendo tal o cual existirá cierta tensión ${ }^{48}$ con la democracia y la idea de igualdad que debiera expresarse en un litigio.

Intentaré ir más lejos que Taruffo e intentar adjudicar expresamente un liberalismo a los garantistas. Para el autor el garantismo viene a ser expresión de un liberalismo a la $\mathrm{Ha}$ $y e k^{49}$, tanto por las nociones políticas que tiene envuelto y en tal sentido me parece apropiado el mote de "neoprivatismo" que le adjudica Barbosa "en una época en que el proceso civil

\footnotetext{
45 Ibid.

${ }^{46}$ PENAA, C. "Democracia liberal", en: Revista Derecho y Humanidades No 14, 2008, p. 33.

${ }_{47}$ Autoritarismo como no liberal y como no democrático.

48 Por supuesto que esa tensión ha intentado ser solucionada por miembros de ambas tradiciones, para ver más en: PEÑA, C. op. cit. (n. 46).

49 No en el sentido de que sigan los ideales de Hayek, sino meramente ha si hay de optar dentro de una clasificación, ocupo la otorgada por Hayek y coloco la tradición, en la liberal en términos de Hayek.
} 
era tenido y habido como "cosa de las partes" (Sache der Parteien, según la conocida expresión alemana), tomamos la libertad de llamarle neoprivatismo", como por la correlación de los valores defendidos por este con el adversary system inglés.

Esto hace a la postura heredera de una inconsistencia particular ${ }^{50}$ con la democracia, "Tanto Rawls como Habermas declaran explícitamente que la inconsistencia entre democracia y liberalismo es una inconsistencia entre dos formas de autonomía, a saber, la autonomía pública por una parte y la autonomía privada por otra parte" 51 , en este caso una tensión de autonomía privada con la noción de igualdad en democracia, que se expresa en el desvalor que representa para los autores la noción de lo público en el proceso, sea cual sea -penal o civil, incluyendo por supuesto al laboral-.

Considero a este punto necesario hacer alguna referencia sobre la tarea que esperamos de los jueces ¿Cuál es el rol que adjudicable a un juez, de tal modo que resulte compatible con esta tènsión democrática?

\section{SOBRE EL ROL DE LOS JUECES}

El profesor Atria, en Jurisdicción y Estado de Derecho, al discutir sobre el rol de los jueces, elabora 3 caricaturas de lo que no es un juez, estas son; juez como autómata, juez activista y juez comisario.

Para efectos de este ensayo, son relevantes las dos primeras. Un juez es un autómata cuando "la identificación de los casos genéricos correlacionados por la ley con soluciones genéricas no es problemática, cuando la realidad es la contraria" ${ }^{2}$. Esto comprende que aun cuando el juez debe aplicar la ley al caso concreto, esta dada su formulación genérica puede tener dos problemas a resolver por el juez al momento de aplicarse, siguiendo a Von Savigny i) problemas de expresión incompleta de la ley, estos son los problemas lógicos y trivialmente entendidos que debe resolver un juez, oscuridades, vacíos, lagunas etc. Estos no presentan ningún problema para la postura garantista, como para cualquier otra. Pero también existe una segunda clase de problema más interesante, ii) los problemas de expresión indetermina$\mathrm{da}$, estos no son propiamente, según Atria, un problema de la ley como el anterior, que permite ser ejemplificado con una ley en abstracto, los problemas de expresión indeterminada son un problema del caso, existe un caso que tiene una particularidad dados sus supuestos de hecho particulares, que no fue considerado por el legislador al momento de formular la norma,

\footnotetext{
${ }^{50}$ Merece un mínimo de rigor teórico decir, que son ambos liberalismo los que tienen una tensión con la idea de democracia, es por esto que han surgido por ejemplo en teoría política las posturas de democracias radicales, he intentado ser lo suficiente prolijo y utilizar una noción de democracia al comienzo de un autor "Liberal", pero el problema se acrecentaría si utilizara definiciones que entiendan el conflicto político por ejemplo a la Mouffe "La profesora Mouffe ha defendido en su obra la idea que en la cultura política contemporánea existe hasta cierto punto una contradicción entre ambas tradiciones, la democrática y la liberal (...) esta tensión simplemente no es posible resolverla mediante las armas ni de la democracia ni del liberalismo", ver: PEÑA, C. op. cit. (n. 46), p 34.

51 PENAA, C. op. cit. (n. 46), p. 34.

52 ATRIA, F. op. cit. (n. 13), p. 18.
} 
"aquí la expresión de la ley si soluciona el caso, por lo que la alternativa que antes no existía ahora si está abierta: puede aplicarse la expresión de la ley -decidir el caso mecánicamente- o puede corregirse la impropiedad de la expresión. Por consiguiente, no podemos decir que la impropiedad ha de ser corregida porque no puede aplicarse la ley de otra manera" 53 .

Como podrá vislumbrarse estos casos presentan un reto mayor, pudiendo afrontarse de dos maneras:

i) No permitimos que un juez tenga la posibilidad de arreglar la impropiedad de la ley, con base en que son los costos de vivir en sociedad y regirnos mediante leyes genéricas. En oros términos abrazamos la forma del derecho en un sentido patológico, caemos en el formalismo.

ii) Permitimos a un juez que repare la impropiedad de la ley, esto fundado en que los intereses legítimos de un sujeto no están siendo considerados al momento de decisión del tribunal, en palabras de Atria "estos casos son relevantes para una sociedad democrática pues en tal caso están siendo utilizados como medios para asegurar la sustentabilidad del Estado de Derecho y "en la medida en que los trata como medios", el derecho no puede pretender legitimidad frente a ellos" 54 .

Consideramos que un juez debe ser algo más que un autómata, por lo que conviene tomar el riesgo de arreglar la expresión impropia con tal de superar el quórum mínimo de igualdad que nos garantiza la democracia, una igualdad que implica que al enfrentarnos a la jurisdicción al menos nuestros intereses sean tomados en cuenta en algún momento, de lo contrario no mostraríamos "el debido respeto por la dignidad de los ciudadanos" (..) "el Estado de derecho, fundado en el reconocimiento de la dignidad de los ciudadanos, exige que la vida, la libertad o la propiedad de un individuo no puedan ser afectadas sin dar ese individuo la posibilidad de que un juez considere su caso" 55 . Esto en parte justifica la pretensión del movimiento publificador, su tensión particular como movimiento con la democracia no lo hace ajeno al problema, en cambio lạ tensión individualista que los garantistas padecen los hace preferir optar por sacrificar los casos especiales en virtud de la forma, sacrificando al caso particular.

Por lo tanto sí vale la pena fortalecer a nuestros jueces, hacer que busquen la verdad, dado que este caso -cualquier caso- podría ser uno de expresión impropia "el juez debe dejarse impresionar por el caso singular ante él, (...) la jurisdicción consiste en dejar que los hechos hablen, en atender al caso para poder apreciarlo en sus propios términos y decidir si es un caso especial o no lo es" 56 . Es a esta dimensión a la que es ciega la postura garantista procesal, optando por jueces pasivos y una renuncia a la búsqueda de la verdad.

\footnotetext{
${ }^{53}$ ATRIA, F. op. cit. (n. 13), p. 26.

${ }^{54}$ ATRIA, F. op. cit. (n. 13), p. 35.

${ }^{55}$ ATRIA, F. op. cit. (n. 13), p. 37.

${ }^{56}$ ATRIA, F. op. cit. (n. 13), p. 3.
} 
Hay que tener presente en cualquier caso que las situaciones de expresión impropia son por definición menores a la mayoría, pues la mayor parte de los casos no pueden ni deben padecer de expresión impropia, si no se coloca en riesgo el sistema en su conjunto y corremos el riesgo de haber convertido a nuestros jueces en activistas, a juicio del autor este miedo postmoderno explica el origen del garantismo procesal.

Un juez es un activista cuando "no cree que lo que a cada uno en derecho corresponda está definitivamente fijado por la ley. Cree que la ley vale en la medida en que es justa o, como se dice hoy en lo que significa lo mismo (...) en la medida en que está en armonía con los derechos fundamentales" 57 , el activista tuerce el sentido de la ley para sus propios fines, para establecer en caso concreto su noción personal de justicia.

Lo problemático del rol del juez radica por tanto en propiciar un modelo que aun cuando no convierta a un juez en "autómata", tampoco permita que este se convierta en un "activista". El problema teórico es grave, pues la distinción de expresión impropia de la ley que antes he mencionado para fundar la necesidad de un juez no autómata, es una distinción invisible a la forma del Derecho.

Siendo así la única forma de detectar a un juez activista versus un juez autómata es la práctica jurisdiccional y es esta la que nos debe alarmar, puesto en efecto han surgido los garantistas que reclaman a final de cuenta, que nuestros procesos se han ordenado de tal forma que tenemos jueces activistas. Esta advertencia no puede ser desatendida, cerrándose el debate a esta postura y generando motes despectivos como "revisionistas".

La crítica garantista debe ser comprendida como un índice crítico relevante sobre la práctica judicial, en los diversos países en que esta ha nacido y ha generado repercusiones, no como un nuevo paradigma teórico que haya logrado derrotar al publicismo, sino como una señal de que no se han implementado de la mejor manera las estructuras procesales, esto especialmente en el nuevo proceso laboral en el cual ya contamos con unos cuantos años de implementación del mismo y han surgido críticas de naturaleza similar.

\section{CONCLUSIONES}

En este trabajo no hemos aceptado el rebatimiento del paradigma procesal publicista pretendido por el garantismo principalmente porque su crítica que tilda de antidemocrática, no es clara en sí misma respecto de la tradición política a la que pertenece, no reconoce la tensión democrática que padece su propio fundamento ideológico, siendo insuficiente desde mi perspectiva, por razones teóricas fundar de manera necesaria su proyecto reformador.

Sin embargo no puede ser descartado de plano su potencial crítico. Ya no hay puntos en que el Derecho procesal civil parezca calmo -podríamos vivir entre activistas y nadie atreverse a señalarlo, por estar contaminados por los supuestos publicistas dogmáticos-. Queda así pendiente resolver si los garantistas han detectado en la práctica acertadamente el problema y más importante queda pendiente comenzar a incluir sus pretensiones de reformas procesales en el debate nacional.

\footnotetext{
${ }^{57}$ ATRIA, F. op. cit. (n. 13), p. 42.
} 
La motivación a lo largo del ensayo ha sido analizar el debate teórico entre garantismo y publicismo, intentando encontrar en el mismo la explicación de las críticas que ha recibido nuestro nuevo proceso laboral y que podría recibir el nuevo proceso civil, en caso de llegar a existir.

He efectuado a lo largo del ensayo una lectura personal del garantismo procesal. Una lectura que espero sea justa con el mismo y valore el aporte intelectual realizado por esta corriente de pensamiento. El garantismo procesal nos interroga acerca de si, persiguiendo la democracia -en sentido_"liberal"- acaso hayamos convertido a nuestros jueces en activistas. Las críticas a la reforma procesal laboral parecieran indicarnos que sí, pero, recalco, parece necesario que sean escritas nuevas páginas para evaluar la veracidad de dichas críticas. Por mi parte, espero al menos haber aportado a esclarecer el sustento teórico de tales prevenciones.

\section{BIBLIOGRAFÍA}

Alvarado, A. "El garantismo procesal". Conferencia pronunciada en el Primer Congreso Nacional de Derecho Procesal Garantista, Azul, 4 y 5 de noviembre de 1999.

ATRIA, F. "Del derecho y el razonamiento jurídico", en: Doxa 22, Alicante, 1999.

ATRIA, F. "Jurisdicción y estado de derecho", borrador "Jurisdicción e independencia judicial: El poder judicial como un poder nulo", en: Revista de Estudios de la Justicia, N ${ }^{\circ}$ 5. Santiago: Universidad de Chile, Facultad de Derecho, 2005.

BENABENTOS, O. Realidad y debido proceso.

BRAVO, B. "Democracia y Liberalismo, de la modernidad a la post modernidad. El problema de su conciliación", en: Revista Derecho y Humanidades, N 14, 2008.

CAPPELETTI, M. El acceso a la justicia. La tendencia en el movimiento mundial para hacer efectivos los derechos. México: Fondo de Cultura Económica, 1996

CORREA, R. "El gobierno judicial ante la constitución", en: Revista de Estudios de la Justicia, $\mathrm{N}^{\circ}$ 6. Santiago: Universidad de Chile, Facultad de Derecho, 2005.

CORREA, R. "Poder judicial y democracia, a rescatar el espíritu del espíritu", en: www.law.yale.edu/intellectuallife/selapublication.html

ETXEBERRIA, J. Las Facultades judiciales en materia probatoria en la LEC. Valencia: Tirant lo Blanch, 2003.

GRANDI, D. La relación Grandi” Código de procedimiento civil italiano 1940, exposición de motivos, Italia, 1940.

Barbosa, J. "El neoprivatismo en el proceso civil", en: MonTero, J. Proceso Civil e Ideologia. Valencia: Tirant lo Blanch, 2006.

MADARIAGA, L.E. "El derecho procesal entre dos ideologías (garantismo vs publicismo): Problemas y perspectivas de desarrollo", en: Revista iberoamericana de derecho procesal garantista, 2007

CIPRIANI, F. "El proceso civil italiano entre revisionistas y negacionistas"; en: MONTERO, J. Proceso Civil e Ideologia. Valencia: Tirant lo Blanch, 2006.

Cipriani, F. "El proceso civil entre viejas ideologías y nuevos eslóganes" en: MONTERO, J. Proceso Civil e Ideologia. Valencia: Tirant lo Blanch, 2006.

CIPRIANI, F. "El autoritarismo procesal (y las pruebas documentales)", en: Ius et Praxis, vol. 13, $\mathrm{N}^{\circ} 2$. Talca: Universidad de Talca, Facultad de Derecho, 2007.

Montero, J. "Prólogo", en: MonTero, J.'Proceso Civil e Ideología. Valencia: Tirant lo Blanch, 2006. 
Montero, J. Proceso Civil e Ideologia. Valencia: Tirant lo Blanch, 2006.

HAYEK, F. "Los principios de un orden social liberal", disponible en: www.cepchile.cl.

MONTELEONE, G. "El actual debate sobre las "orientaciones publicisticas" del proceso civil" en⿳亠 MONTERO, J. Proceso Civil e Ideologia. Valencia: Tirant lo Blanch, 2006.

MONTEleone, G. "Principios e ideologías del proceso civil: Impresiones de un revisionista", en: MONTERO, J. Proceso Civil e Ideología. Valencia: Tirant lo Blanch, 2006.

PICO, J. "El derecho procesal entre el garantismo y la eficacia: Un debate mal planteado", en: MONTERO, J. Proceso Civil e Ideología. Valencia: Tirant lo Blanch, 2006.

VERDE, G. "Las ideologías del proceso en un reciente ensayo", en: MONTERO, J. Proceso Civil e Ideologia. Valencia: Tirant lo Blanch, 2006.

MOUfFE, C. En torno a lo politico, Editorial Paidós Estado y Sociedad.

Palavecino, C. "El retorno del inquisidor. Las potestades judiciales en materia probatoria en el procedimiento laboral chileno", en: Revista laboral chilena $\mathrm{N}^{\circ}$ 173, 2009.

PEŃA, C. "Democracia liberal", en: Revista Derecho y Humanidades, N 14, 2008.

PROST, R. Democracia e igualdad, disponible en: www.law.yale.edu/intellectuallife/selapublication.html

PUlgar, C. "¿Existe un Derecho Procesal del Trabajo?”, en: Boletín Oficial de la Dirección del Trabajo, 2005. Santiago, febrero 2006.

SANTA, J.J. Sistema del derecho soviético. Buenos Aires: Roque Depalma, 1957.

SCHUCK, P. "El poder judicial en una democracia", disponible en www.law.yale.edu/intellectuallife/selapublication.html

SCHONK, A. Derecho Procesal Civil. Barcelona: Bosch Casa Editorial, 1950.

TARUffo, M. "Racionalidad y crisis de la ley procesal", en: Doxa 22, 1999.

UGARTE, J.L. Tutela de derechos fundamentales. Santiago: LegalPublishing, 2009. 